\title{
Intumescent silicone-based coatings for the fire protection of carbon fiber reinforced composites
}

\author{
SERGE BOURBIGOT, BASTIEN GARDELLE AND SOPHIE DUQUESNE \\ ISP/UMET UMR 8207 \\ Ecole Nationale Supérieure de Chimie de Lille, University of Lille \\ Av. Mendeleïev, CS 90108 \\ 59652 Villeneuve d'Ascq, France \\ serge.bourbigot@ensc-lille.fr
}

\begin{abstract}
The application of carbon fiber reinforced polymer (CFRP) in aircraft structure has introduced potential fire threats and fire protection must be provided. In this paper, intumescent silicone based-coatings (low and high intumescing coatings) are evaluated on CFRP using a bench developed in the laboratory mimicking a jet fuel fire occurring at high heat flux $\left(200 \mathrm{~kW} / \mathrm{m}^{2}\right)$. It is shown the development of large intumescence (high intumescing coating) associated with appropriate thermal properties of the coating (heat conductivity measured as low as $0.3 \mathrm{~W} / \mathrm{m} . \mathrm{K}$ ) provides efficient protection for the CFRP at the jet fire test. On the other hand, the formation of cohesive ceramic (low intumescing coating) with low heat conductivity (constant heat conductivity as a function of temperature of $0.35 \mathrm{~W} / \mathrm{m} . \mathrm{K}$ ) also provides protection but its efficiency is lower than that of intumescent char. It is evidenced that intumescent silicone-based coatings are materials of choice for protecting CFRP in the case of jet fuel fire.
\end{abstract}

KEYWORDS: intumescence, fire chemistry, protection of composite, silicone-based coating

\section{INTRODUCTION}

Energy efficient mobility is now driving the use and consumption of fiber-reinforced structural polymeric materials to reduce weight in transportation (aircraft, train, truck and car). In particular, carbon fiber reinforced composites are becoming materials of choice because of their superior mechanical performance and fatigue resistance [1]. Composite materials are increasingly being used in the design of aircraft and they have attracted attention of researchers and industrial manufacturers to be used in primary structural components of aircrafts such as Boeing 787 or the coming Airbus A350. However, this recent application of carbon fiber reinforced polymer (CFRP) in aircraft structure has introduced potential fire threats and it raises concerns regarding fire safety in both the in-flight and post-crash environments [2, 3]. The fire hazard has then led to the enforcement of stringent fire safety regulations by aviation authorities on the use of composites.

When CFRPs are exposed to a jet fuel fire, the composite materials degrade and quickly ignite, releasing volatile gases, and producing char resulting in a significant reduction in structural strength. It is common practice by fire scientists to quantify the intensity of a fire by the radiant heat flux rather than flame temperature [3]. There is an approximate relationship between fire type and heat flux, and examples are: (i) small smoldering fire: $2-10 \mathrm{~kW} / \mathrm{m}^{2}$; (ii) trash can fire: $10-50 \mathrm{~kW} / \mathrm{m}^{2}$; (iii) cabin fire: $50-100 \mathrm{~kW} / \mathrm{m}^{2}$; (iv) post-flashover cabin fire: $>100 \mathrm{~kW} / \mathrm{m}^{2}$ and $(\mathrm{v})$ jet fuel fire: $150-200 \mathrm{~kW} / \mathrm{m}^{2}$. In this research we are interested in the fire behavior of CRFP undergoing jet fuel fire and how to protect it.

The main issue with CFRP is its susceptibility to softening and failure in the event of fire. They decompose in high temperature environments such as those created by fire and so, it leads to distortion and weakening of the composite structure which can ultimately cause failure. In the field of fire protection of CFRP for aeronautic applications, two main properties have to be considered. First, the composite must not ignite on its back side and the mechanical properties of the composite have to be maintained when exposed to fire. Second, the temperature of the CFRP has not to reach the glass transition temperature of the epoxy resin. For these reasons, CFRP must be thermally insulated especially when engine compartments (where fuel leakage can occur) or the fuselage (in the case of post-crash fire) are concerned. The fire protection of CFRPs can be achieved with reactive insulation coatings which react when exposed to fire increasing their thermal insulation properties, thereby protecting the underlying substrate. It happens with intumescent coatings which expand and form an insulative layer at the surface of the substrate upon heating. The 
intumescence process results from a combination of charring and foaming at the surface of the substrate [4]. The result of this process is the formation of a multicellular (alveolar) barrier, thick and nonflammable, which likely to protect the substrate or residual material from heat or flame action. The charred layer acts as a physical barrier which slows down heat and mass transfer between gas and condensed phase. The formation of an intumescent char is a complicated process involving several critical aspects: rheology (expansion phase, viscoelasticity of char), chemistry (charring) and thermophysics (limitation of heat and mass transfer) [5]. This approach will be considered in this paper and only the ignition of the composite and temperature on the backside during fire testing will be evaluated.

Recently Mouritz et al $[6,7]$ reported the use of conventional organic intumescent paints to protect composite structures from fire and it appeared as successful. In previous work, we have shown that intumescent silicone based-coating is very efficient to protect steel in the case of hydrocarbon fire scenarios $[8,9]$. As far as we know, this type of coating has never been evaluated for the fire protection of composites while exhibiting numerous advantages compared to the conventional organic intumescent paints. Silicones have the properties to exhibit low thermal conductivity, to be water and heat resistant, to evolve few toxic gases during their degradation and to have high durability: they are therefore materials of choice for aircraft applications. The main goal of this paper is to investigate the performance of intumescent silicone-based coatings for the fire protection of CFRP in the case of jet fuel fire. The first part of the paper will present the fire behavior of the materials using a bench developed in the lab mimicking jet fire occurring at high heat flux $\left(200 \mathrm{~kW} / \mathrm{m}^{2}\right)$. The second part will evaluate physical parameters of the intumescent silicone-based coating including the heat conductivity as a function of temperature and the dynamic of expansion during the test. The third part will investigate the fire degradation of the intumescent coating protecting the composite from a chemical point of view and finally, a mechanism of protection will be discussed.

\section{EXPERIMENTAL}

\section{Materials}

The silicone resin was composed of a hydroxylated PDMS with a viscosity of $80 \mathrm{cS}$ (viscosity was measured using cone/plate rheometer CP-52), methyltrimethoxysilane (MTM) as crosslinking agent and a titanium catalyst. All the materials were supplied by Dow Corning, Seneffe (Belgium). Several fillers were incorporated in the silicone resin: expandable graphite (ES350F5 from Graphitwerk Kropfmuehl (Germany)) with an average particle size of $300 \mu \mathrm{m}$; an organo-clay (Cloisite 30B; C30B) supplied by Southern Clay Products, San Antonio-TX (USA); a ground calcium carbonate (GCC) stearic acid coated with an average particle size of $4.5 \mu \mathrm{m}$ supplied by Dow Corning Seneffe (Belgium). The composition of the formulations is shown in Table 1.

Table 1. Composition of the intumescent silicone-based coatings

\begin{tabular}{|l|c|c|}
\hline Silicone formulation & F1 - High intumescing coating & F2- Low intumescing coating \\
\hline Silicone matrix & $56 \%$ & $56 \%$ \\
\hline Expandable graphite & $25 \%$ & - \\
\hline Calcium carbonate & $12 \%$ & $37 \%$ \\
\hline Clay & $7 \%$ & $7 \%$ \\
\hline
\end{tabular}

Formulations were coated onto CFRP (carbon fiber reinforced epoxy resin supplied by Goodfellow) having the dimensions of $150 \times 150 \times 35 \mathrm{~mm}^{3}$. The glass transition temperature $\left(\mathrm{T}_{\mathrm{g}}\right)$ of the epoxy resin is about $200^{\circ} \mathrm{C}$ (data of the manufacturer). Two thicknesses of silicone-based coating were tested: $500 \pm 100 \mu \mathrm{m}$ and $1000 \pm 100 \mu \mathrm{m}$.

\section{Jet fire bench}

The jet fire bench intends to mimic at the small-scale jet fuel fire which can be caused by burning jet fuel external to the aircraft as a result of fuel tank damage during the impact of an aircraft or by jet fuel fire occurring in the engine nacelle. The measurements were carried out using a constant heat flux test provided by a propane burner (10kW propane burner) delivering a heat flux of $200 \mathrm{~kW} / \mathrm{m}^{2}$ on CFRP. The heat flux was calibrated with a water cooled calorimeter TG 1000-1A from Vatell Corporation. $150 \mathrm{~mm}$ square 
CFRP were placed in a vermiculite 'picture frame' that enabled a $100 \mathrm{~mm}$ square central region to be exposed to the heat flux. The purpose of the frame was to minimize effects due to the burning of volatiles around the edge of the sample. CFRP was lightly clamped on vermiculite frame with screws on the edges insulated with silica wool. Thermocouples (4 K-type thermocouples) were placed on the back side of CFRP to measure the temperature as a function temperature during the test. The set-up is shown Fig. 1.

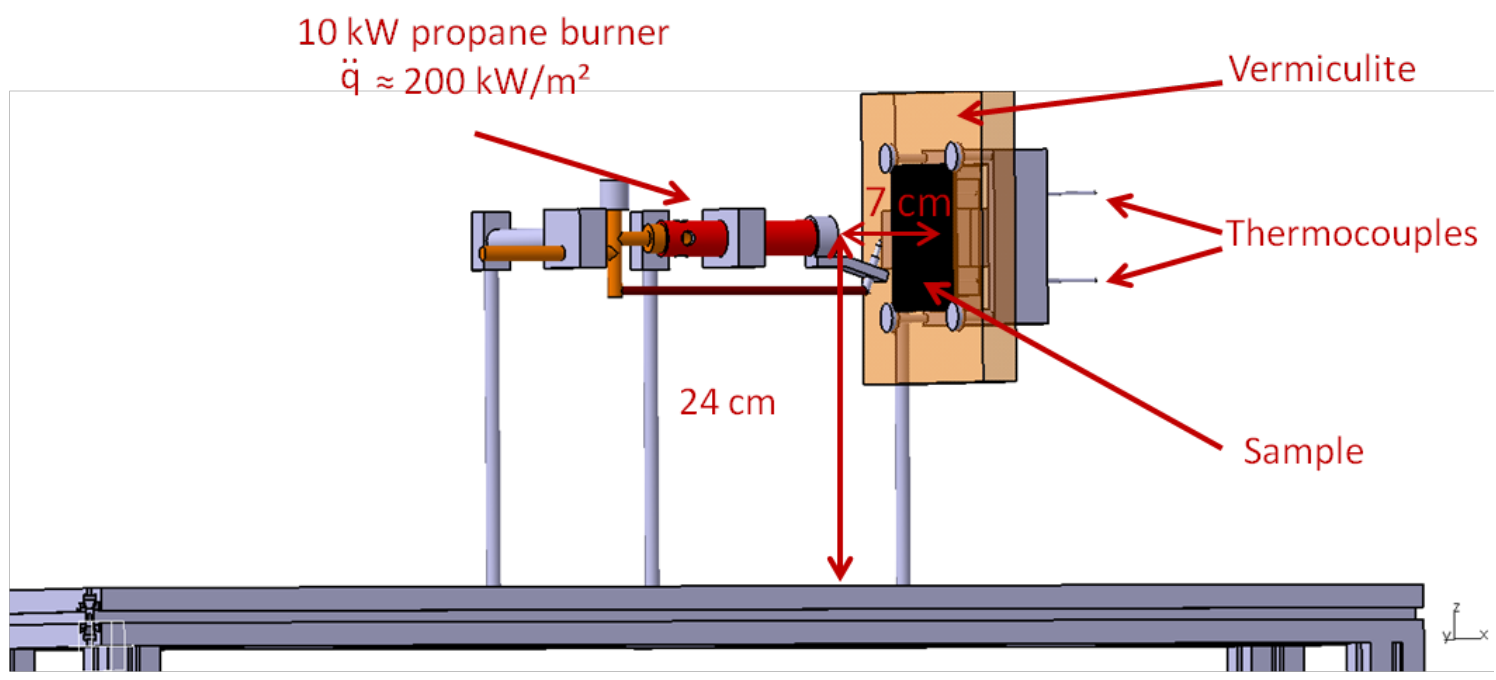

Fig. 1. Schematic view of the jet fire bench

\section{Expansion measurement}

In order to determine the expansion rate of the intumescent coating, the development of the char was monitored by an infrared camera (FLIR System A40) during the fire test. The advantage of infrared camera is to give high contrast to make image analysis. Using image analysis in dynamic conditions (from the movie), expansion of the intumescent coating can be measured and quantified. The pictures captured from the movie were analyzed by Image J software (NIH, Bethesda, MD) and the expansion of the coating was measured. In this approach, it is assumed for the calculation on images that the expansion is homogeneous and occurs in one dimension (which is reasonable, see Fig. 2).

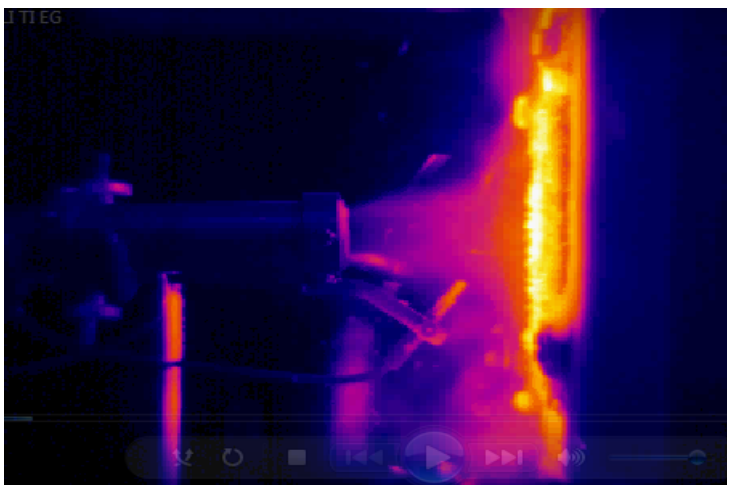

(a)

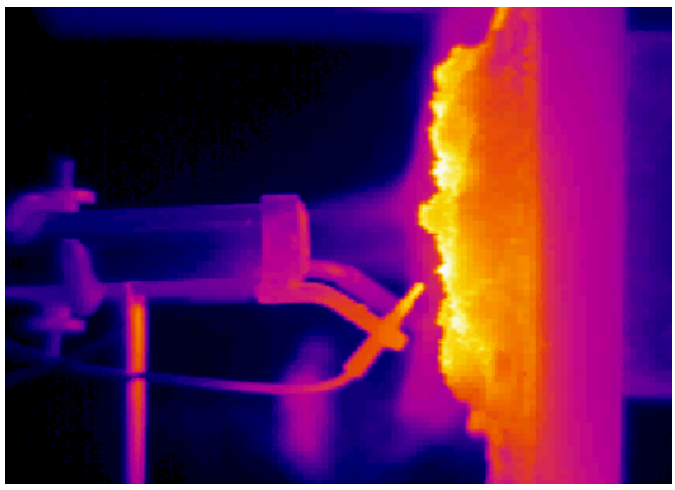

(b)

Fig. 2. Infrared images of CFRP protected by the intumescent silicone-based coating during the jet fire test at (a) $40 \mathrm{~s}$ and at (b) $900 \mathrm{~s}$ 


\section{Thermal conductivity}

Thermal conductivity material was measured from $25^{\circ} \mathrm{C}$ to $700^{\circ} \mathrm{C}$ using a hot disk thermal constant analyzer (Hot Disk TPS 2500 S) from Thermoconcept (Bordeaux, France), which is a transient plane source technique [10]. The sensor which is warmth emitter and thermocouple is directly molded in the coating disk to ensure a good contact between the sample and the sensor during the experiment. The temperature is stabilized each $100.0^{\circ} \mathrm{C}$ with less than $0.1^{\circ} \mathrm{C}$ deviation. The conductivity measurements were made by applying a power of $0.03-0.15 \mathrm{~W}$ for between 5 and $60 \mathrm{~s}$, depending on the thermal conductivity of the sample. The experimental set up is illustrated in Fig. 3. All experiments were carried out in inert atmosphere to prevent the oxidation of the sensor.

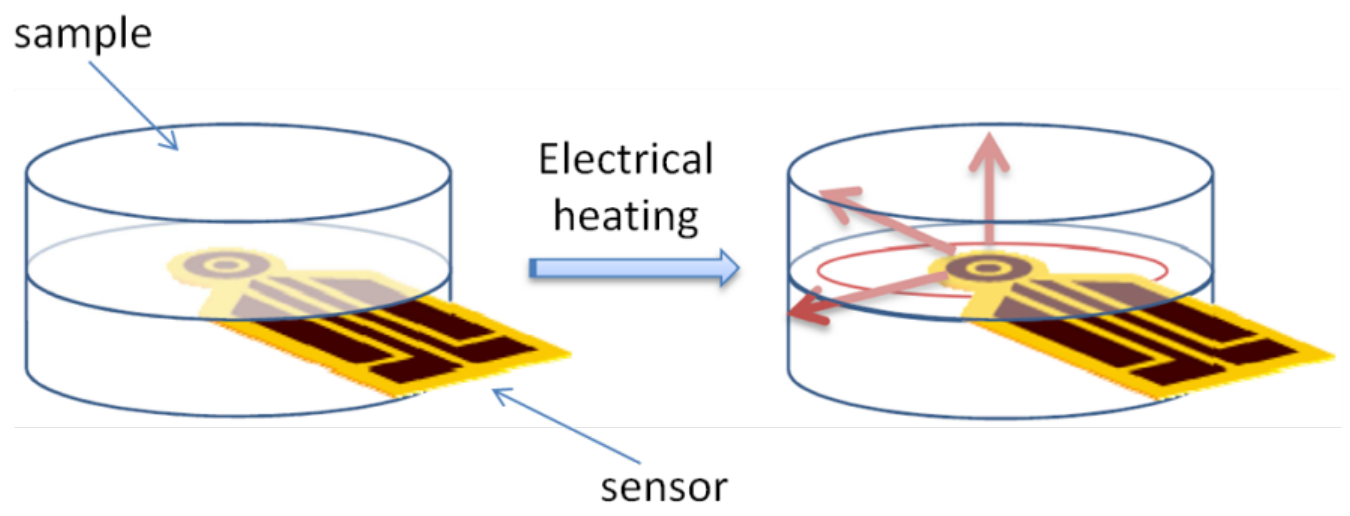

Fig. 3. Hot disk technology set up

\section{Spectroscopic analyses}

Two spectroscopic analyses were used (X-ray photoelectron spectroscopy (XPS) and ${ }^{29} \mathrm{Si}$ solid state nuclear magnetic resonance (NMR)) to determine the changes of the chemical composition and of the structure of the coating residue after furnace testing. These techniques can distinguish several kinds of structures including D, T and Q structures which characterize silicone network (Fig 4).

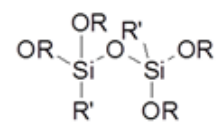

$\mathrm{T}^{1}$ structure

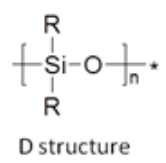<smiles>[R][Si]([R])(O)O[Si]([R])([R])O[Si]([R])([R])OC</smiles>

$T^{2}$ structure

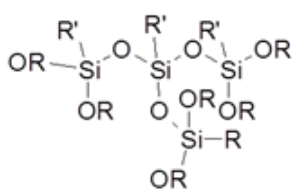

$\mathrm{T}^{3}$ structure

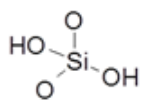

$\mathrm{Q}^{2}$ structure<smiles>O[Si](O)(O)O</smiles>

$\mathrm{Q}^{4}$ structure<smiles>CC(C)([Mg])Cl</smiles>

Fig.4: Schematics presentation of $\mathrm{D}, \mathrm{T}^{\mathrm{i}}$ and $\mathrm{Q}^{\mathrm{i}}$ silicone structures

XPS experiments were carried out on an ultra-high vacuum KRATOS Axis Ultra spectrometer using the mono-chromatized $\mathrm{Al} \mathrm{K} \alpha(1486.6 \mathrm{eV})$ source. Constant analyzer pass energy of $40 \mathrm{eV}$ was used. The full width at half maximum (FWHM) was restrained to be equal in both $\mathrm{Si}_{2 \mathrm{p} 3 / 2}$ and $\mathrm{Si}_{2 \mathrm{p} 1 / 2}$ peaks, and the area of the peak assigned to $\mathrm{Si}_{2 \mathrm{p} 1 / 2}$ was restrained to be half the area of the $\mathrm{Si}_{2 \mathrm{p} 3 / 2}$. The energy separation between the $\mathrm{Si}_{2 \mathrm{p} 3 / 2}$ and $\mathrm{Si}_{2 \mathrm{p} 1 / 2}$ doublet is constant and is $0.6 \mathrm{eV}$. Simulation of the experimental peaks was carried out using the Gaussian-Lorentzian mixture from CasaXPS software. 
${ }^{29} \mathrm{Si}$ solid state NMR is a powerful tool for examining silicon surrounding. ${ }^{29} \mathrm{Si}$ NMR spectra were recorded on a Bruker Advance II 400 operating at $9.4 \mathrm{~T}$ and using a $7 \mathrm{~mm}$ probe. Zirconia rotor and caps were used. NMR spectra were acquired with MAS (magic angle spinning) of $5 \mathrm{kHz}$. The reference used for ${ }^{29} \mathrm{Si}$ NMR was tetramethylsilane (TMS). For the pure clay sample, a delay of $30 \mathrm{~s}$ between the pulses and a $\pi / 2$ pulse of $6 \mathrm{~ms}$ were used and 2560 scans were accumulated. For F2 residue sample after jet fire testing, a delay of $180 \mathrm{~s}$ between the $\pi / 2$ pulses (pulse of $180 \mathrm{~s}$ ) were used and 128 scans were accumulated to get an acceptable signal to noise ratio.

Moreover, X-ray diffraction (XRD) patterns were recorded in the $10^{\circ}-80^{\circ} 2 \theta$ range using a Bruker Advanced D8 diffractometer $\left(\lambda_{\mathrm{Cu}-\mathrm{K} a}=1.5418 \AA\right.$ ) in configuration $\theta / 2 \theta$. The acquisition parameters were as follows: a step of $0.02^{\circ}$, a step time of $2 \mathrm{~s}$. The data are analyzed using the diffraction, patterns of inorganic crystal structure database.

\section{RESULTS AND DISCUSSION}

\section{Evaluation of the fire protection}

Two types of fire protective coating (thickness $=500 \mu \mathrm{m}$ ) were applied on CFRP. The formulation F1 corresponds to formulation containing expandable graphite and so, it exhibits high expansion when undergoing high thermal constraint [9]. On the contrary, the composition of the F2 formulation mainly contains GCC acting as intumescent ingredient releasing $\mathrm{CO}_{2}$ at high temperature $\left(600^{\circ} \mathrm{C}<\mathrm{T}<700^{\circ} \mathrm{C}\right)$ and its expansion is quite low even if we have shown that this formulation provides significant protection of steel in the case of torch test [11]. The formulations were evaluated at the jet fuel fire test and the fire behavior of the two coatings at different times is shown in Table 2. The virgin CFRP burns with high flames when applying the burner and is completely pierced after 100s. CFRP-F1 exhibits an intumescent behavior which provides an efficient protection while CRFP-F2 wraps up and the coating does not expand.

Table 2. Fire behavior of virgin CFRP compared to fire protected CFRP as a function of time during the jet fuel fire test (thickness of the coating $=500 \mu \mathrm{m}$ )

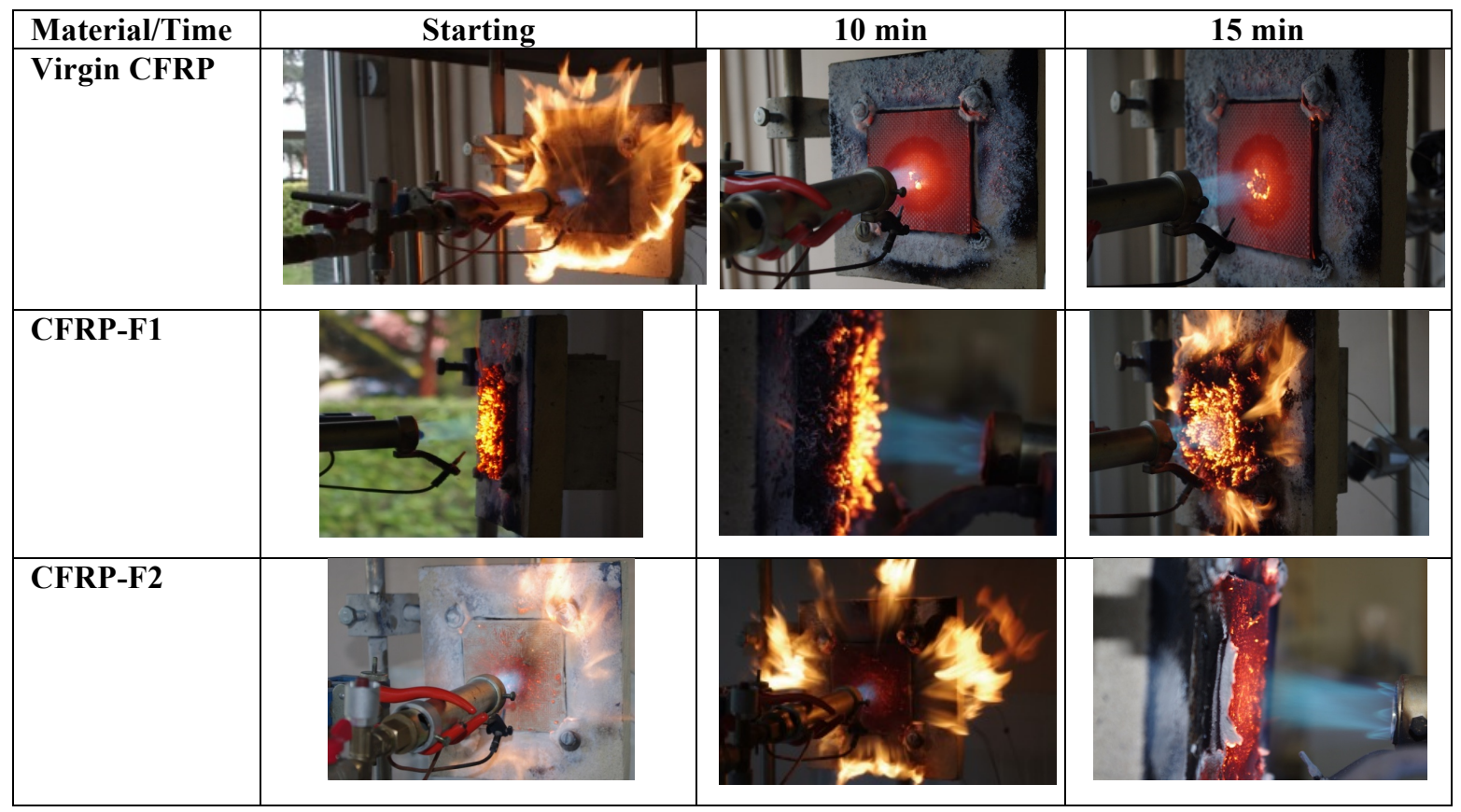

Fig. 5 shows the temperature on the backside of the samples as a function of time. When temperature raises up suddenly it indicates the ignition of the composite on the backside. For a thickness of $500 \mu \mathrm{m}$ (Fig. 5(a)), it is clearly shown that the F1 intumescent coating provides the most efficient protection since the 
ignition of the composite backside occurs at 460s while it is at 260s and 100s for CFRP-F2 and virgin CFRP respectively. If $1000 \mu \mathrm{m}$ intumescent coating is applied on CFRP, the composite is well protected: its backside is not pierced and it does not ignite (Fig. 5-(b)). It is also noteworthy the F1 formulation provides higher protection compared to the F2 formulation since temperature on the backside of CFRP-F1 is always lower than that of CFRP-F2 with an average temperature difference of about $70^{\circ} \mathrm{C}$ (Fig. 5-(b)).

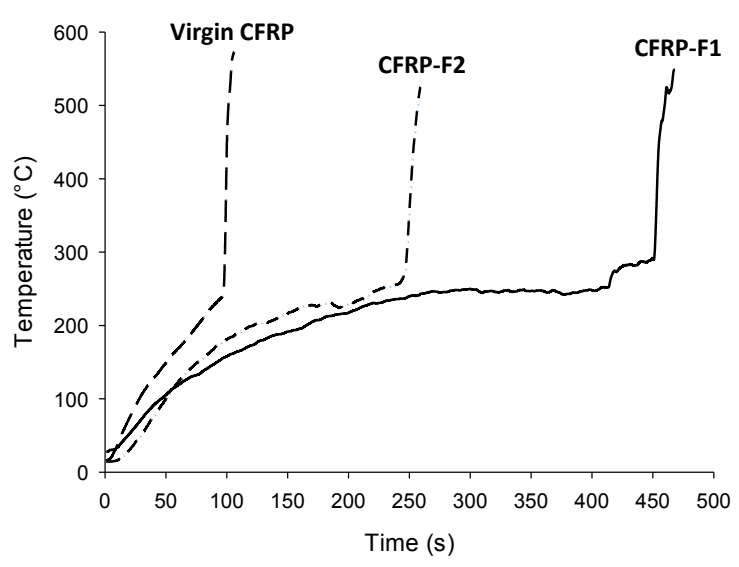

(a)

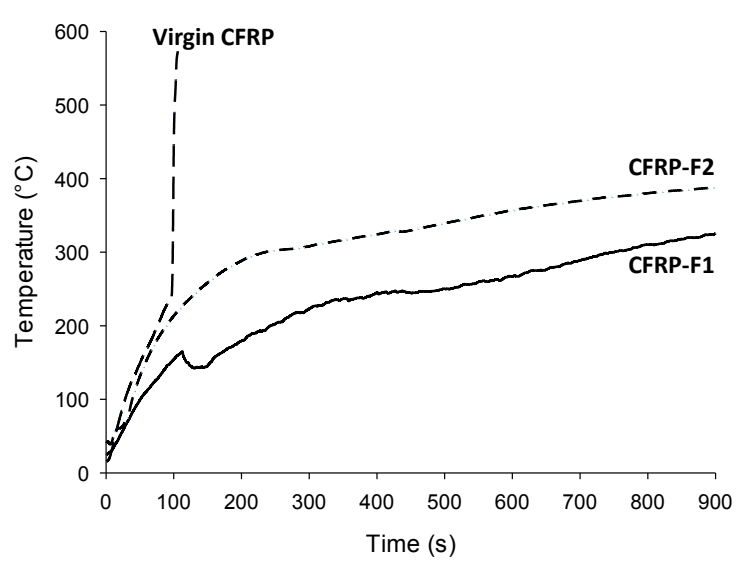

(b)

Fig. 5. Temperature as a function of time of intumescent CFRPs compared to virgin CFRP (backside temperature) during the jet fire test at coating thickness of (a) $500 \mu \mathrm{m}$ and of (b) $1000 \mu \mathrm{m}$

The observation of the residues after the jet fuel fire test gives information on the mode of protection of the intumescent coatings (Table 3 ).

The virgin CFRP leaves the woven carbon fibers and epoxy resin is completely degraded. High expansion (about $2400 \%$ ) of the intumescent coating is observed in the case of CFRP-F1. With $500 \mu \mathrm{m}$ of coating thickness, epoxy resin is almost completely degraded and the residue is constituted by carbon fiber plies and the expanded char. At higher coating thickness $(1000 \mu \mathrm{m})$, the intumescent char is cohesive (no destruction due to the impact of the flame) and the epoxy resin is only partially degraded evidencing the efficiency of the protection. For CFRP-F2, partial decohesion of the coating (not expanded) is observed with the complete degradation of the epoxy resin $(500 \mu \mathrm{m}$ thick coating). With a $1000 \mu \mathrm{m}$ thick coating, the residue is a porous not expanded char which has partially protected the epoxy resin (not complete degradation of epoxy resin). In each cases, the glass transition temperature of the epoxy resin is reached and we can thus assume that the mechanical properties of the composite after fire testing are strongly modified. However, this study evidenced that the fire protection of CFRP using intumescent silicone based coating is very effective. 
Table 3. Residues of the samples after 900 s at the jet fire test

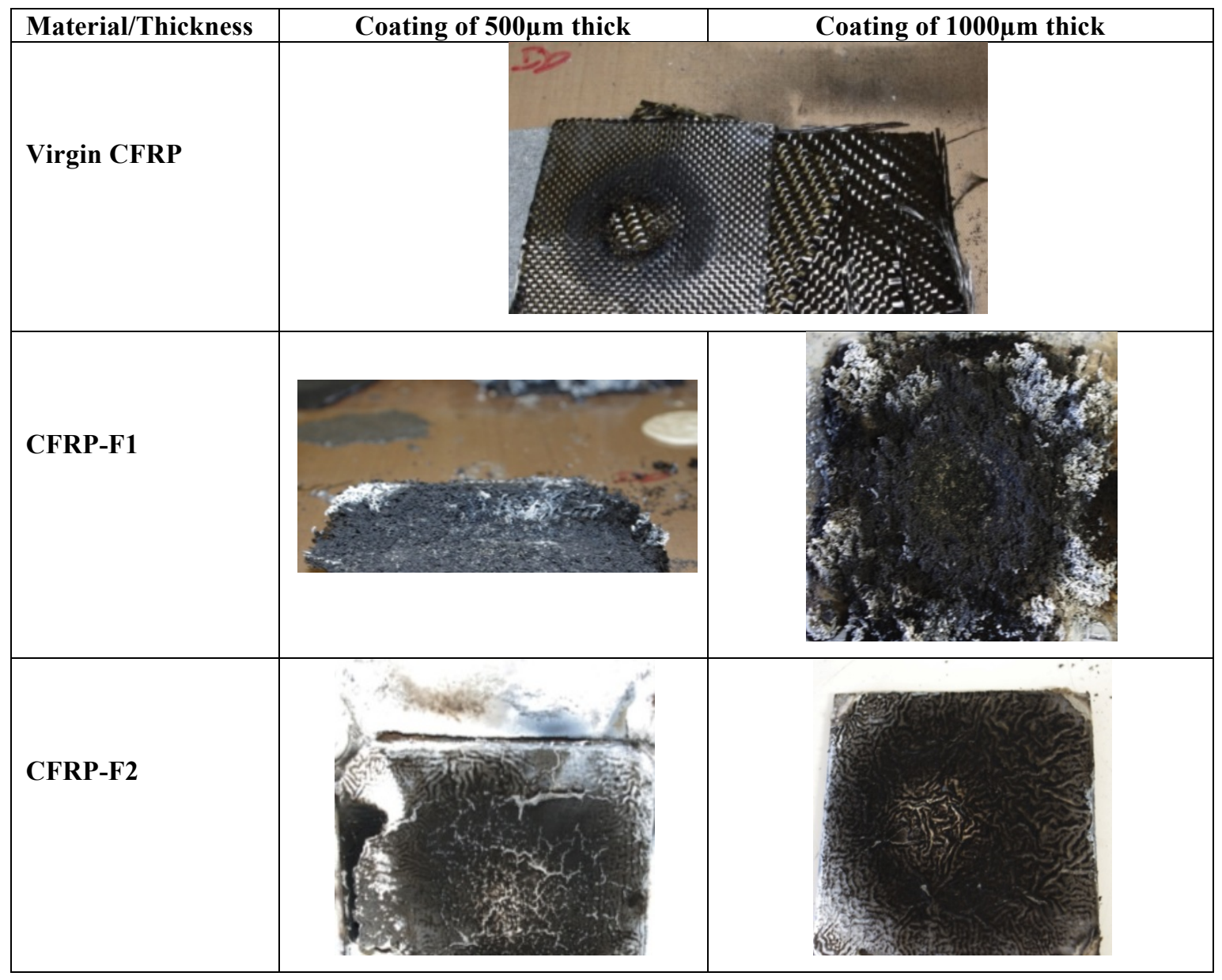

\section{Physical parameters of the intumescent coatings}

An intumescent material reacts upon heating to produce gases that are partially trapped in a viscoelastic matrix. The matrix expands as gases are produced (the blowing agent and/or the degradation products of the polymeric matrix) and at the same time, cross-linking reactions and charring cause the matrix to harden thereby producing a coherent highly porous char. The porosity of the char is generally extremely high that the resulting structure has extremely low thermal conductivity. The most important parameters of the expanded char affecting its thermal insulation performance are its heat conductivity and its ability to swell rapidly [12]. Those two parameters are then measured in the following.

No significant expansion is observed in the case of CFRP-F2 and so, only the expansion of CFRP-F1 as a function of time was measured (Fig. 6). The intumescent coating expands rapidly up to $2400 \%$ at the beginning of the experiment and reaches a stationary state at 120 s. Its expansion rate is measured at $23 \% / \mathrm{s}$ (average value). 


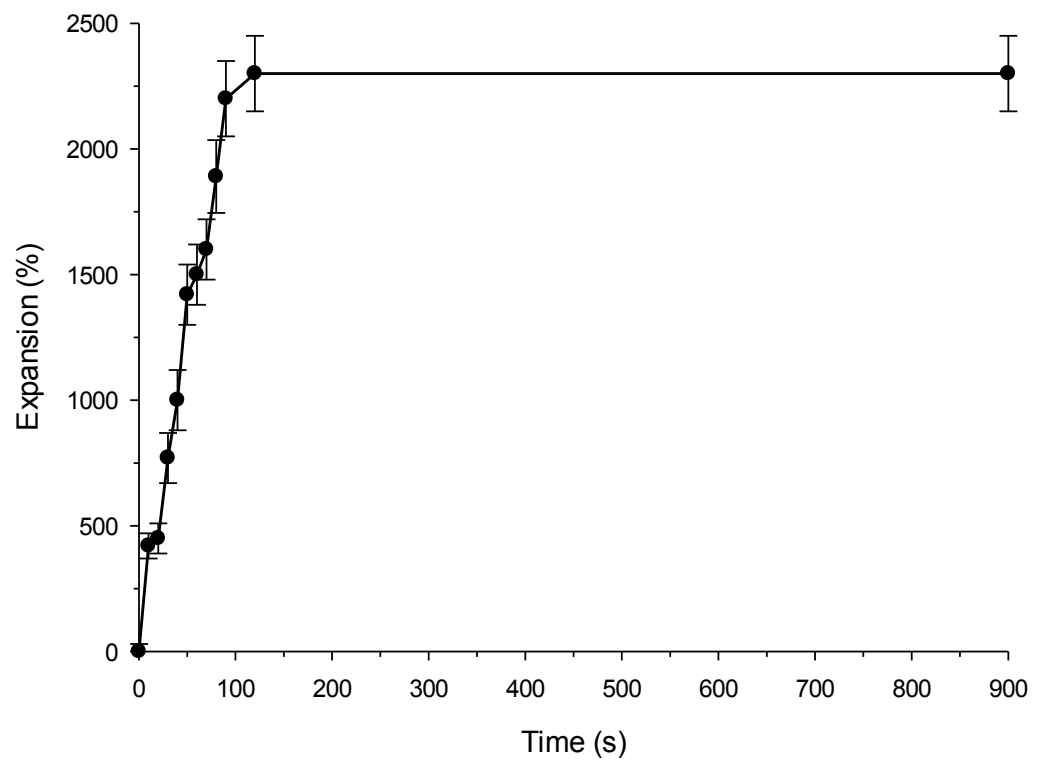

Fig. 6. Expansion as a function of time of CFRP-F1 measured during the jet fire test

Very few article in the literature deals with the measurement of thermal conductivity at high temperature of intumescent material. J.E.J Staggs determined thermal conductivities of intumescent char at high temperature by numerical simulation [13]. He reported that thermal conductivity of intumescent char material varies from $0.1 \mathrm{~W} / \mathrm{m}$.K. to $0.4 \mathrm{~W} / \mathrm{m} . \mathrm{K}$. from ambient temperature to $600^{\circ} \mathrm{C}$. In previous work, we measured similar values on intumescent coatings $[8,9]$. In the case of the intumescent formulations F1 and F2 (measurement done on the coatings without CFRP), heat conductivity is as low as $0.3 \mathrm{~W} / \mathrm{m} . \mathrm{K}$ (Fig. 7) and is in the range of values already reported for intumescent coatings. Nevertheless two distinct behaviors are observed. Heat conductivity of F2 is constant as a function of temperature (average value of 0.35 $\mathrm{W} / \mathrm{m} . \mathrm{K}$ ) while that of $\mathrm{F} 1$ decreases when temperature increases (heat conductivity drops down from 1 $\mathrm{W} / \mathrm{m} . \mathrm{K}$ to $0.35 \mathrm{~W} / \mathrm{m} . \mathrm{K}$ between 20 to $300^{\circ} \mathrm{C}$ ). This last behavior is characteristic of intumescent material: when temperature goes up the material expands and forms an alveolar structure of low heat conductivity. The low expansion of F2 does not permit to lower heat conductivity while the high expansion of F1 associated to the formation of multicellular reduces heat conductivity. It is also noteworthy that the heat conductivity of F1 is much higher than that of F2 $(1 \mathrm{~W} / \mathrm{m} . \mathrm{K}$ vs. $0.3 \mathrm{~W} / \mathrm{m} . \mathrm{K})$ probably because of the high loading of expandable graphite in the F1 formulation. The heat conductivity of bulk graphite is indeed as high as $1000 \mathrm{~W} / \mathrm{m} . \mathrm{K}[14]$. 


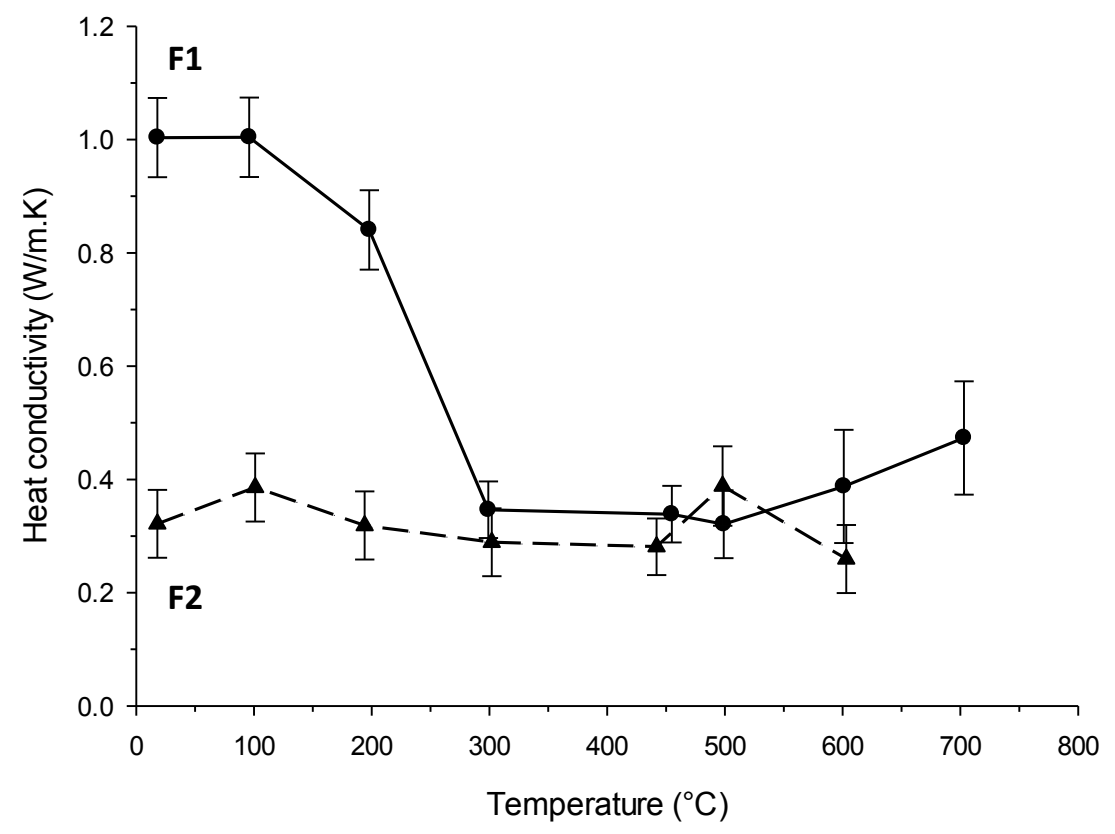

Fig. 7. Heat conductivity as a function of temperature of the formulations F1 and F2

\section{Chemical characterization of the intumescent residues}

The residues of the two formulations were analyzed in order to determine the mechanism of charring during the jet fire test. The two residues exhibit two different structures (Fig. 8). The residue of the F1 formulation is composed of worm-like pieces embedded in white coating. The worms come from expandable graphite. Expandable graphite is a graphite intercalation compound in which sulfuric acid and/or nitric acid is inserted between the carbon layers of graphite. Upon heating, exfoliation of the graphite occurs, i.e. expansion along c-axis of the crystal structure by about hundred times [15]. The material generated in that way is a puffed-up material of low density with a "worm" like structure. According to previous work [9], the white part could be due to the adsorption of silica at the surface of the graphite worm. It will be discussed in the following. The F2 formulation does not contain expandable graphite and the residue exhibits a coral-like structure which is porous.

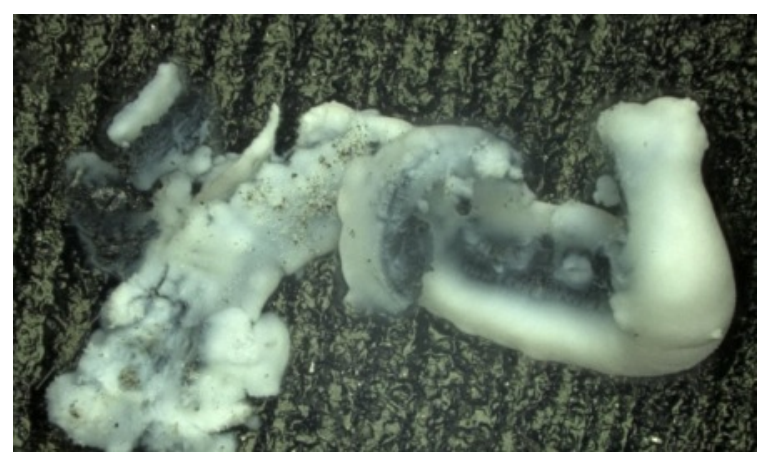

(a)

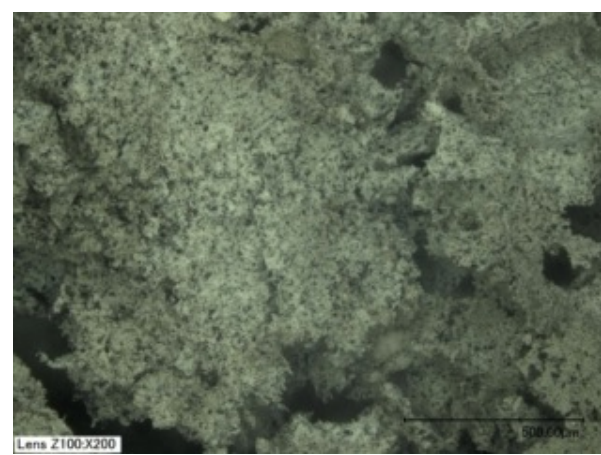

(b)

Fig. 8. Numerical pictures (magnification $\mathrm{x} 200$ ) of the residues of (a) formulation F1 and of (b) formulation F2 after the jet fire test

The residues were further characterized by XPS, XRD and ${ }^{29} \mathrm{Si}$ NMR (only for F2 residue). XPS and ${ }^{29} \mathrm{Si}$ NMR spectra obtained are presented in Fig. 9. ${ }^{29} \mathrm{Si}$ NMR spectrum evidences the formation of $\mathrm{T}$ and $\mathrm{Q}^{4}$ structures characterized by the peaks at $-70 \mathrm{ppm}$ and $-110 \mathrm{ppm}$ and therefore the formation of a cross- 
linked silica network. Fig. 9b) and c) show $\mathrm{Si}_{2 \mathrm{p}}$ spectra of the residues of the F1 and F2 formulations after the jet fire test. They exhibit a broad band between 98 and $106 \mathrm{eV}$ suggesting the presence of several components. After deconvoluting the two spectra, the resulting bands were assigned according to the literature $[16,17]$ using the usual nomenclature of $\mathrm{D}, \mathrm{T}$ and $\mathrm{Q}$ structures (Table 4).

For F2 residue (Fig 9b), three main components have been identified by binding energies at $101.7 \pm 0.2 \mathrm{eV}$, $102.9 \pm 0.2 \mathrm{eV}$ and $103.8 \pm 0.2 \mathrm{eV}$ corresponding to respectively calcium silicate, $\mathrm{T}$ and $\mathrm{Q}$ structures (from the thermal degradation of silicone). It is consistent with ${ }^{29} \mathrm{Si}$ NMR showing $\mathrm{T}$ and $\mathrm{Q}$ structures in the F2 residue. The $\mathrm{Si}_{2 \mathrm{p} 3 / 2}$ band at $101.7 \mathrm{eV}$ is assigned to calcium silicate species (Q structure) since no $\mathrm{D}$ structure have been identified by ${ }^{29} \mathrm{Si}$ NMR and the $\mathrm{Si}_{2 \mathrm{p} 3 / 2}$ band at $103.8 \mathrm{eV}$ is assigned to silicates with $\mathrm{SiO}_{4}$ tetrahedra of various polymerization types [18].

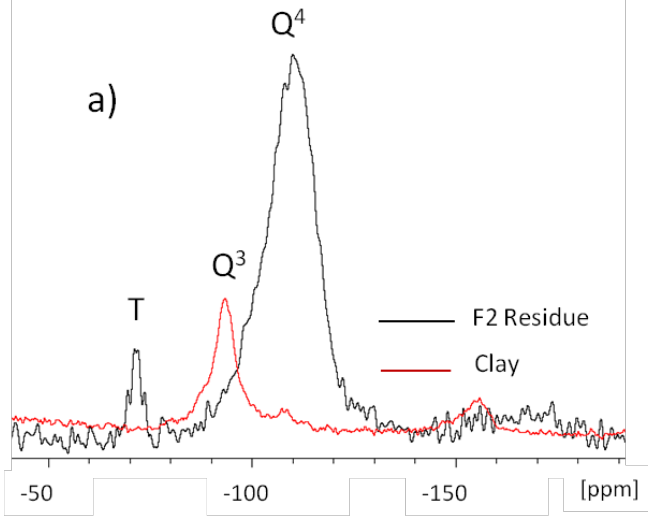

b)
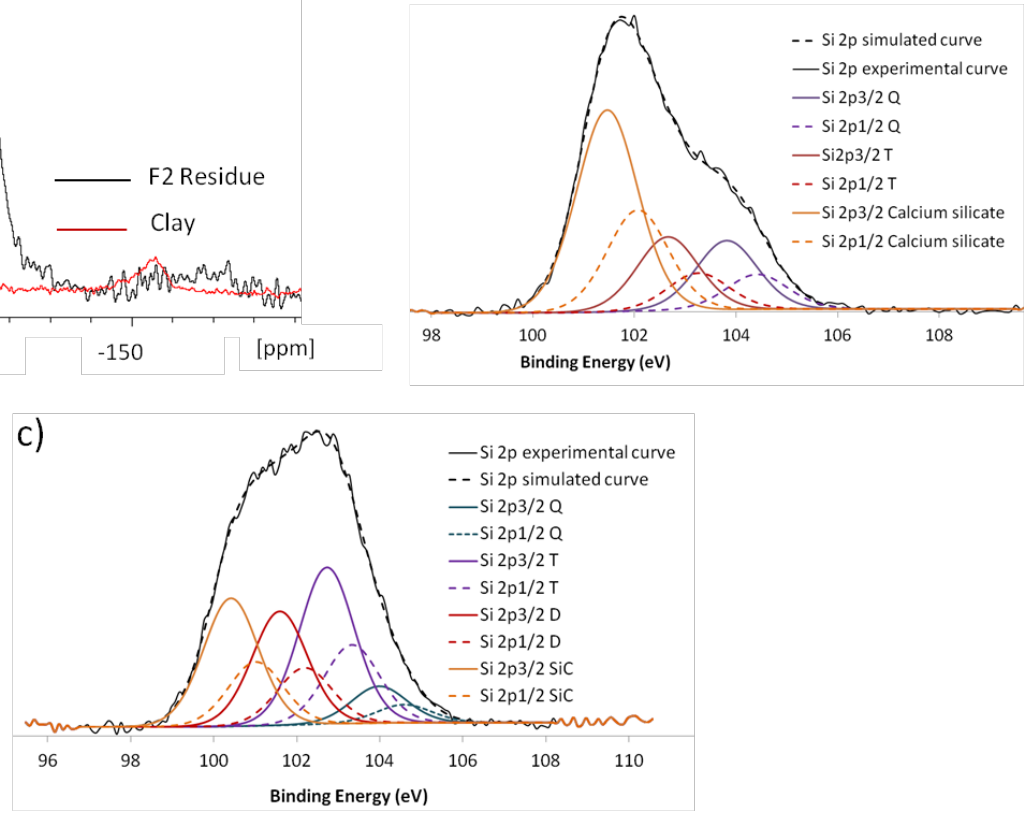

Fig. 9. a) ${ }^{29} \mathrm{Si}$ NMR spectrum of clay and $\mathrm{F} 2$ residue and $\mathrm{Si}_{2 \mathrm{p}}$ XPS spectra of the residues of (b) formulation $\mathrm{F} 2$ and of (c) formulation F1 after the jet fire test

F1 residue (Fig 9c) is composed of $\mathrm{T}$ and $\mathrm{Q}$ structures (coming from the degradation of the silicone matrix [9]) characterized by two $\mathrm{Si}_{2 \mathrm{p} 3 / 2}$ binding energies at $102.6 \mathrm{eV}$ and $103.7 \mathrm{eV}$. The formation of silicon carbide $(\mathrm{SiC})$ is also observed characterized by the band at a $\mathrm{Si}_{2 \mathrm{p} 3 / 2}$ binding energy of $100.6 \mathrm{eV}$. The band at $101.6 \mathrm{eV}$ corresponds to D structure and also to calcium silicate as for F2 residue. Note the formation of silicone carbide is due to interactions between graphite and silicone during the fire degradation which leads to the formation of coated graphite flakes reinforcing the cohesion of the structure (Fig 8) [9].

Table 4. Binding energy and assignment of the species characterized in the intumescent residues after the jet fire test

\begin{tabular}{|c|c|c|c|c|}
\hline Silicone structures & $\mathbf{S i C}$ & $\mathbf{D}\left(\mathbf{S i O}_{\mathbf{2} / \mathbf{2}}\right)$ & $\mathbf{T}\left(\mathbf{S i O}_{\mathbf{3} / \mathbf{2}}\right)$ & $\mathbf{Q}\left(\mathbf{S i O}_{\mathbf{4} / 2}\right)$ \\
\hline F1 Residue & $100.4 \pm 0.2 \mathrm{eV}$ & $101.6 \pm 0.2 \mathrm{eV}$ & $102.7 \pm 0.2 \mathrm{eV}$ & $103.9 \pm 0.2 \mathrm{eV}$ \\
\hline Silicone structures & - & $\begin{array}{c}\text { Calcium } \\
\text { silicate }\end{array}$ & $\mathbf{T}\left(\mathbf{S i O}_{\mathbf{3} / \mathbf{2}}\right)$ & $\mathbf{Q}(\mathbf{S i O 4} / \mathbf{2})$ \\
\hline F2 Residue & - & $101.7 \pm 0.2 \mathrm{eV}$ & $102.9 \pm 0.2 \mathrm{eV}$ & $103.8 \pm 0.2 \mathrm{eV}$ \\
\hline
\end{tabular}


Additional characterization by XRD was done on the residues to examine the changes of $\mathrm{CaCO}_{3}$ in the formulations and the XRD patterns of the two residues are shown on Fig. 10. They evidence the partial decarbonation of calcium carbonate into calcium oxide and it suggests the formation of calcium silicate which is consistent with the XPS analysis (Fig 10-(b)). Because of the high content and the high crystallinity of graphite, the intensities of the peaks related to Ca-based compounds are less intense than those of graphite (Fig. 10-(a)).

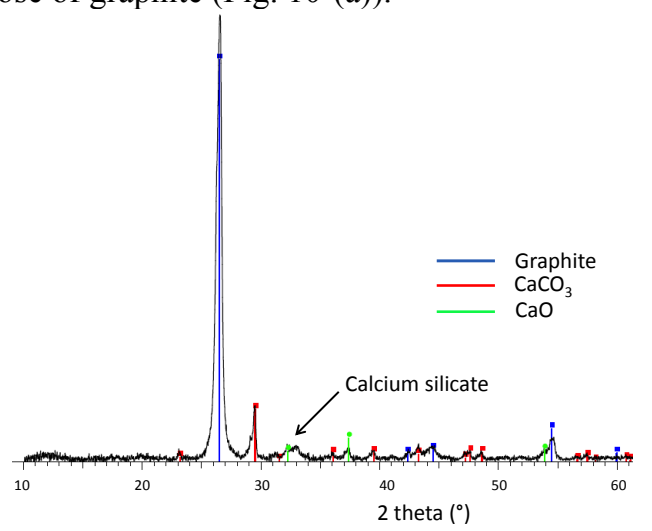

(a)

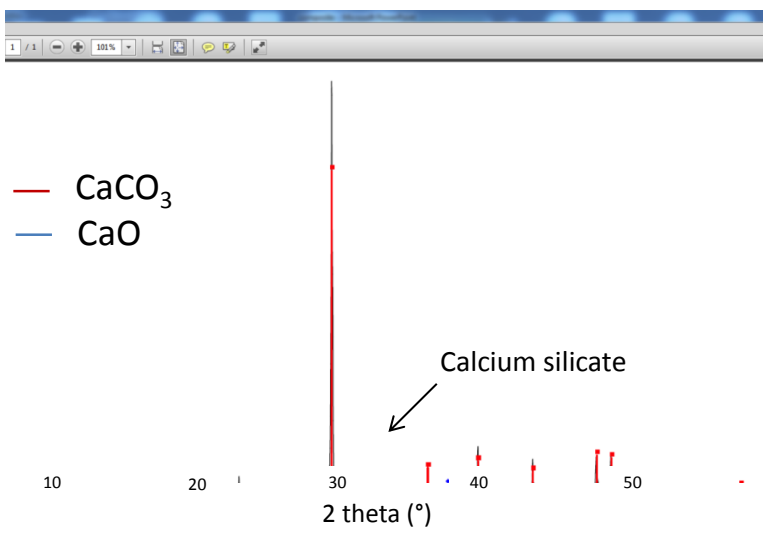

(b)

Fig. 10. XRD Characterization of the F1 (a) and F2 (b) residues

\section{Mechanism of protection}

F1 and F2 formulations applied on CFRP provide an efficient protection at the jet fire test when the coating is thick enough $(1000 \mu \mathrm{m})$. Visual observation of the fire behavior at the jet fire reveals two modes of protection. F1 formulation produces a high expanded char while F2 formulation does not expand and forms a compact residue. The incorporation of expandable graphite in silicone permits the formation of an intumescent char upon heating. Its high expansion rate delivers rapidly the protection of interest. Associated to its low heat conductivity, the high expanded intumescent char (2400\%) limits heat transfer from the flame to CFRP. In terms of chemistry, the analyses have shown Q structures which indicate the formation of cross-linked silica network. This silica network coats the graphite worms and provides superior cohesion to the intumescent layer. Recent work done in our group has shown this cohesion was reinforced by the presence of clay in the formulation [19]. This reinforcement takes place thanks to specific reactions between the hydroxyl groups of the clay and the silicone and also, with intercalation of the silicone chains into the galleries of the clay leading to the presence of the clay in the whole part of the char. The role of $\mathrm{CaCO}_{3}$ is not completely elucidated but we may assume it permits the formation of an additional protective ceramic formed by calcium silicate, calcium oxide and non decarbonated calcium carbonate.

F2 formulation does not contain expandable graphite and its expansion upon heating is thus limited. The degradation of the silicone does not yield any cross-linked silica structure but to a ceramic constituted by calcium silicate, calcium oxide and non decarbonated calcium carbonate. The degraded silicone can act as a binder which can provide cohesion to the coating. This coating has good insulative properties exhibiting low heat conductivity even at high temperature $\left(0.3 \mathrm{~W} / \mathrm{m} \cdot \mathrm{K}\right.$ at $\left.600^{\circ} \mathrm{C}\right)$.

\section{CONCLUSION}

This paper has investigated the fire protection of CFRP using novel intumescent silicone-based coatings. A small scale test mimicking jet fuel fire was developed for examining the fire behavior of intumescent coated CFRPs. It is shown the development of large intumescence associated with appropriate thermal properties of the coating (low heat conductivity) provides efficient protection at the jet fire test. The formation of cohesive ceramic with low heat conductivity also provides protection but its efficiency is lower than that of intumescent char. It is therefore evidenced intumescent silicone-based coatings are materials of choice for protecting CFRP in the case of jet fuel fire. 


\section{REFERENCES}

[1] Tavares, S. M. O., Camanho, P., and De Castro, P. M. S. T. (2013) Assessment of materials for fuselage panels considering fatigue behavior. 265-270

[2] Sikoutris, D. E., Vlachos, D. E., Kostopoulos, V., Jagger, S., and Ledin, S., (2012) Fire burnthrough response of CFRP aerostructures. Numerical investigation and experimental verification. Applied Composite Materials, 19(2):141-159, doi:10.1007/s10443-011-9187-x

[3] La Delfa, G., Luinge, J. W., and Gibson, A. G., (2009) Integrity of composite aircraft fuselage materials under crash fire conditions. Plastics, Rubber and Composites, 38(2-4):111-117, doi:10.1179/174328909X387900

[4] Bourbigot, S., Le Bras, M., Duquesne, S., and Rochery, M., (2004) Recent advances for intumescent polymers. Macromolecular Materials and Engineering, 289(6):499-511, doi:10.1002/mame.200400007

[5] Jimenez, M., Duquesne, S., and Bourbigot, S., (2006) Multiscale experimental approach for developing high-performance intumescent coatings. Industrial and Engineering Chemistry Research, 45(13):4500-4508, doi:10.1021/ie060040x

[6] Kandare, E., Griffin, G. J., Feih, S., Gibson, A. G., Lattimer, B. Y., and Mouritz, A. P., (2012) Fire structural modelling of fibre-polymer laminates protected with an intumescent coating. Composites Part A: Applied Science and Manufacturing, 43(5):793-802, doi:10.1016/j.compositesa.2011.05.012

[7] Mouritz, A. P., Feih, S., Kandare, E., and Gibson, A. G., (2013) Thermal-mechanical modelling of laminates with fire protection coating. Composites Part B: Engineering, 48:68-78, doi:10.1016/j.compositesb.2012.12.001

[8] Gardelle, B., Duquesne, S., Rerat, V., and Bourbigot, S., (2013) Thermal degradation and fire performance of intumescent silicone-based coatings. Polymers for Advanced Technologies, 24(1):6269, doi:10.1002/pat.3050

[9] Gardelle, B., Duquesne, S., Vandereecken, P., and Bourbigot, S., (2013) Characterization of the carbonization process of expandable graphite/silicone formulations in a simulated fire. Polymer Degradation and Stability, 98(5):1052-1063, doi:10.1016/j.polymdegradstab.2013.02.001

[10] Gustavsson, M. K., and Gustafsson, S. E. (2008) Different ways of evaluating thermal transport properties from measurements with the transient plane source (hot disk) method. 397-402

[11] Gardelle, B., Duquesne, S., Vandereecken, P., and Bourbigot, S. (2012). "Fire performance of curable silicone-based coatings." ACS Symposium Series: Fire and Polymer, C. A. Wilkie, A. B. Morgan, and G. L. Nelson, eds., American Chemical Society, Washington, 205-221.

[12] Bourbigot, S., Turf, T., Bellayer, S., and Duquesne, S., (2009) Polyhedral oligomeric silsesquioxane as flame retardant for thermoplastic polyurethane. Polymer Degradation and Stability, 94(8):1230-1237, doi:10.1016/j.polymdegradstab.2009.04.016

[13] Staggs, J. E. J., (2010) Thermal conductivity estimates of intumescent chars by direct numerical simulation. Fire Safety Journal, 45(4):228-237, doi:10.1016/j.firesaf.2010.03.004

[14] Nika, D. L., and Balandin, A. A., (2012) Two-dimensional phonon transport in graphene. Journal of Physics Condensed Matter, 24(23), doi:10.1088/0953-8984/24/23/233203 
[15] Duquesne, S., Le Bras, M., Bourbigot, S., Delobel, R., Camino, G., Eling, B., Lindsay, C., and Roels, T., (2001) Thermal degradation of polyurethane and polyurethane/expandable graphite coatings. Polymer Degradation and Stability, 74(3):493-499, doi:10.1016/S0141-3910(01)00177-X

[16] O'Hare, L. A., Parbhoo, B., and Leadley, S. R., (2004) Development of a methodology for XPS curvefitting of the Si 2p core level of siloxane materials. Surface and Interface Analysis, 36(10):1427-1434, doi:10.1002/sia.1917

[17] Contarini, S., Howlett, S. P., Rizzo, C., and De Angelis, B. A., (1991) XPS study on the dispersion of carbon additives in silicon carbide powders. Applied Surface Science, 51(3-4):177-183, doi:10.1016/0169-4332(91)90400-E

[18] Okada, K., Kameshima, Y., and Yasumori, A., (1998) Chemical shifts of silicon X-ray photoelectron spectra by polymerization structures of silicates. Journal of the American Ceramic Society, 81(7):1970-1972

[19] Gardelle, B., Duquesne, S., Vandereecken, P., Bellayer, S., and Bourbigot, S., (2013) Mode of action of organoclay on the fire performance of intumescent silicone based coating. Progress in Organic Coatings, submitted 